\title{
ASTHMA
}

\section{Comparison of atopic cough with cough variant asthma: is atopic cough a precursor of asthma?}

\author{
M Fujimura, H Ogawa, Y Nishizawa, K Nishi
}

Thorax 2003;58:14-18

See end of article for authors' affiliations

$\ldots \ldots \ldots \ldots \ldots \ldots$.

Correspondence to: Dr M Fujimura, Third

Department of Internal Medicine, Kanazawa University School of

Medicine, Kanazawa 920-8641, Japan;

fujimura@med3.m.

kanazawa-u.ac.jp

Revised version received 9 July 2002

Accepted for publication

17 August 2002

\begin{abstract}
Background: We have described a group of patients who present with isolated chronic bronchodilator resistant non-productive cough with an atopic constitution, eosinophilic tracheobronchitis, and airway cough receptor hypersensitivity without bronchial hyperresponsiveness, which we have termed "atopic cough". Although cough variant asthma (in which the cough responds to bronchodilators) is recognised as a precursor of typical asthma, it is not known whether atopic cough is also a precursor of asthma.

Methods: Eighty two patients with atopic cough were retrospectively examined for onset of typical asthma and compared with 55 patients with cough variant asthma (20 untreated patients and 35 treated with long term inhaled beclomethasone dipropionate (BDP), 218-467 $\mu \mathrm{g} /$ day). The median follow up period for patients with atopic cough and cough variant asthma was $4.8(1-11.5)$ years and $3.7(1-12.4)$ years, respectively.

Results: Onset of typical asthma occurred in only one of the patients with atopic cough. In patients with cough variant asthma, typical asthma developed in two of 35 patients taking BDP and six of 20 untreated patients (difference $24.3 \%, 95 \% \mathrm{Cl} 2.8$ to $45.8, \mathrm{p}<0.02$ ).

Conclusions: These findings suggest that cough variant asthma is a precursor of typical asthma but that atopic cough is not. Treatment with inhaled steroids may prevent the transformation of cough variant asthma into typical asthma.
\end{abstract}

C ough variant asthma, gastro-oesophageal reflux associated cough, and postnasal drip induced cough are well known causes of chronic non-productive cough. ${ }^{1}$ In 1992 we proposed the existence of a bronchodilator resistant non-productive cough associated with atopy which we termed "atopic cough". ${ }^{2}$ Cough variant asthma and atopic cough are major causes of isolated chronic non-productive cough in Japan. ${ }^{3}$ Gastro-oesophageal reflux associated cough and postnasal drip induced cough, which are major causes of chronic cough in Western countries, ${ }^{1}$ are very rare in Japan. ${ }^{4}$ In our case series ${ }^{3}$ cough variant asthma was identified in $40.1 \%$ and atopic cough in $58.3 \%$ of patients with isolated chronic non-productive cough referred to respiratory specialists. The pathological characteristics of atopic cough include eosinophilic tracheobronchitis without bronchoalveolar lavage (BAL) eosinophilia, and the physiological characteristics of atopic cough include cough hypersensitivity without bronchial hyperresponsiveness (BHR). ${ }^{5}$ Conversely, cough variant asthma ${ }^{6}$ appears to be similar to asthma, with mild BHR and eosinophilic inflammation of central and peripheral airways, and a cough responsive to bronchodilator treatment. ${ }^{7}$

Johnson and Osborn ${ }^{8}$ reported that a significant proportion of patients diagnosed with cough variant asthma eventually develop wheezing, sometimes severe enough to require continuous bronchodilator therapy. Corrao et al reported that two of six patients with cough variant asthma began wheezing within 18 months of completing the study. Braman and Corrao $^{9}$ restudied 16 patients diagnosed with cough variant asthma $3-5$ years earlier and found that $37 \%$ of these patients had developed intermittent wheezing during the study period. As nearly $30 \%$ of patients with cough variant asthma have been found to develop typical asthma, cough variant asthma has been considered a precursor of typical asthma. However, the evolution of atopic cough, particularly with regard to its progression to typical asthma, has not been elucidated. Determining whether atopic cough is a precursor of asthma may be important ${ }^{10}$ as early intervention in asthma, including the use of inhaled steroids, may prevent exacerbations and airway remodelling. ${ }^{11}$ Since a high percentage of patients with cough variant asthma develop typical asthma, it may be beneficial to treat them with inhaled steroids. It is important to establish whether the outcomes of cough variant asthma and atopic cough are different as atopic cough may not require regular treatment with inhaled steroids.

With these considerations in mind, we retrospectively examined the outcome of patients with atopic cough, particularly the onset of typical asthma, and compared them with patients with cough variant asthma with or without long term treatment with inhaled steroids.

\section{METHODS}

\section{Patients}

Eighty two patients ( 19 men) aged 14.4-44.3 years with atopic cough and 55 patients (16 men) aged 14.8-46.4 years with cough variant asthma who had been diagnosed and treated in our hospitals formed the study groups. Their clinical records were examined retrospectively.

\section{Atopic cough}

The diagnosis of atopic cough was made according to the following criteria proposed by the Japanese Cough Research Society (tables 1 and 2 ):

(1) Non-productive cough lasting more than 8 weeks without wheezing or dyspnoea.

(2) Presence of one or more findings indicative of atopy, including a past history and/or complications of allergic diseases excluding asthma, a peripheral blood eosinophilia $(\geqslant 6 \%$ or $\geqslant 400$ cells $/ \mu \mathrm{l})$, raised total IgE level in the serum $(\geqslant 200 \mathrm{IU} / \mathrm{ml})$, positive specific IgE antibody to aeroallergens, and positive allergen skin test and/or induced sputum eosinophilia $(\geqslant 2.5 \%)$.

(3) No bronchial reversibility, defined as less than a $10 \%$ increase in forced expiratory volume in 1 second $\left(\mathrm{FEV}_{1}\right)$ after 
Table 1 Pulmonary function, capsaicin cough threshold (C5), methacholine bronchial responsiveness $\left(\mathrm{PC}_{20}\right.$ ), and bronchial reversibility in patients with atopic cough and cough variant asthma

\begin{tabular}{|c|c|c|c|c|c|c|c|c|}
\hline & $\operatorname{Sex}(M / F)$ & Age (years) & FVC (\% pred) & $\mathrm{FEV}_{1}$ (\% pred) & $\begin{array}{l}\mathrm{FEV}_{1} / \mathrm{FVC} \\
\text { ratio }(\%)\end{array}$ & C5 $(\mu \mathrm{M})$ & $\mathrm{PC}_{20}(\mathrm{mg} / \mathrm{ml})$ & $\begin{array}{l}\text { Bronchial } \\
\text { reversibility (\% } \\
\text { increase) }\end{array}$ \\
\hline \multicolumn{9}{|l|}{ Atopic cough } \\
\hline Definite & $6 / 18$ & 48.7 (12.0) & $106.0(14.8)$ & $100.6(14.4)$ & $78.7(7.6)$ & $\begin{array}{l}0.70 \\
(1.47)^{* * * *}\end{array}$ & $\begin{array}{l}43.3 \\
(1.33)^{* * * *}\end{array}$ & $4.2(2.2)^{* \star *}$ \\
\hline Probable & $13 / 45$ & $42.6(15.2)$ & $106.6(12.2)$ & 100.7 (16.3) & $81.8(6.4)$ & $\begin{array}{l}1.73 \\
(1.64)^{* * * *}\end{array}$ & $15.3(1.34)^{* * *}$ & $3.4(4.3)^{* * * *}$ \\
\hline Total & $19 / 63$ & $44.3(14.4)$ & $106.4(12.9)$ & $106.6(15.6)$ & $80.8(6.9)$ & $\begin{array}{l}1.22 \\
(1.61)^{* * * *}\end{array}$ & $\begin{array}{l}22.1 \\
(1.25)^{* * * *}\end{array}$ & $3.7(3.7)^{* * * *}$ \\
\hline \multicolumn{9}{|c|}{ Cough variant asthma } \\
\hline With BDP & $10 / 25$ & $44.1(14.9)$ & $105.7(17.5)$ & $95.7(15.2)$ & $79.2(7.7)$ & $8.60(1.33)$ & $4.46(1.35)$ & $9.3(6.0)$ \\
\hline Without BDP & $6 / 14$ & $51.4(13.9)$ & $106.6(12.3)$ & $101.3(13.3)$ & $77.2(7.6)$ & $12.0(1.39)$ & $2.94(1.47)$ & $7.1(5.1)$ \\
\hline Total & $16 / 39$ & $46.7(14.8)$ & $106.0(15.7)$ & $97.8(14.7)$ & $78.5(7.6)$ & $9.73(1.24)$ & $3.83(1.26)$ & $8.6(5.8)$ \\
\hline
\end{tabular}

$\mathrm{FEV}_{1}=$ forced expiratory volume in 1 second; $\mathrm{FVC}=$ forced vital capacity; $\mathrm{C} 5=$ provocative concentration of capsaicin eliciting five or more coughs: $\mathrm{PC}_{20}=$ provocative concentration of methacholine causing a $20 \%$ or more fall in $\mathrm{FEV}_{1}$; bronchial reversibility=percentage increase from baseline in $\mathrm{FEV}_{1}$ after $300 \mu \mathrm{pg}$ salbutamol following $250 \mathrm{mg}$ aminophylline.

Data are expressed as mean (SD) except for $C 5$ and $\mathrm{PC}_{20}$ which are expressed as geometric mean (SE) values.

$* * * p<0.001,{ }^{* * *} p<0.0001 v$ all patients with cough variant asthma.

Table 2 Cough sensitivity, bronchial responsiveness, bronchial reversibility, and findings indicative of atopic constitution in study subjects

\begin{tabular}{|c|c|c|c|c|c|c|c|c|}
\hline & \multicolumn{4}{|c|}{ Atopic cough } & \multicolumn{4}{|c|}{ Cough variant asthma } \\
\hline & \multicolumn{2}{|l|}{ Definite } & \multicolumn{2}{|c|}{ Probable } & \multicolumn{2}{|c|}{ With BDP } & \multicolumn{2}{|c|}{ Without BDP } \\
\hline & Yes/No & Not tested & Yes/No & Not tested & Yes/No & Not tested & Yes/No & Not tested \\
\hline (1) Heightened cough sensitivity (C5 $\leqslant 3.9 \mu M)$ & $24 / 0$ & 0 & $33 / 16$ & 9 & $12 / 19$ & 4 & $2 / 15$ & 3 \\
\hline (2) Bronchial hyperresponsiveness ( $\left.\mathrm{PC}_{20}<10 \mathrm{mg} / \mathrm{ml}\right)$ & $0 / 24$ & 0 & $15 / 33$ & 10 & $35 / 0$ & 0 & $20 / 0$ & 0 \\
\hline (3) Increased bronchial reversibility ( $\geqslant 10 \%$ ) & $0 / 24$ & 0 & $1 / 50$ & 7 & $13 / 15$ & 7 & $3 / 11$ & 6 \\
\hline $\begin{array}{l}\text { (4) Peripheral blood eosinophilia ( } \geqslant 6 \% \text { and/or } \\
\geqslant 400 / \mu l)\end{array}$ & $8 / 16$ & 0 & $27 / 31$ & 0 & $13 / 22$ & 0 & $8 / 12$ & 0 \\
\hline (5) Sputum eosinophilia ( $\geqslant 2.5 \%$ ) & $7 / 4$ & $13(9)^{*}$ & $16 / 10$ & $32(17)^{*}$ & $9 / 13$ & $13(10)^{*}$ & $6 / 4$ & $10(8)^{*}$ \\
\hline (6) Increased total lgE ( $\geqslant 200 \mathrm{IU} / \mathrm{ml}$ ) & $9 / 15$ & 0 & $24 / 34$ & 0 & $15 / 20$ & 0 & $8 / 12$ & 0 \\
\hline (7) Positive specific lgE & $10 / 14$ & 0 & $27 / 31$ & 0 & $21 / 14$ & 0 & $11 / 9$ & 0 \\
\hline (8) Positive skin test & $3 / 3$ & 18 & $6 / 12$ & 40 & $1 / 2$ & 32 & $1 / 0$ & 19 \\
\hline $\begin{array}{l}\text { (9) Positive past history and/or complication of allergic } \\
\text { disease }\end{array}$ & $19 / 5$ & 0 & $46 / 12$ & 0 & $24 / 11$ & 0 & $14 / 6$ & 0 \\
\hline (10) Positive for one or more of (4)-(9) & $24 / 0$ & 0 & $58 / 0$ & 0 & $33 / 2$ & 0 & $17 / 3$ & 0 \\
\hline
\end{tabular}

inhalation of $300 \mu \mathrm{g}$ salbutamol sulphate following intravenous administration of $250 \mathrm{mg}$ aminophylline.

(4) Bronchial responsiveness within normal limits (provocative concentration of methacholine causing a $20 \%$ fall in $\mathrm{FEV}_{1}$ $\left.\left(\mathrm{PC}_{20}\right) \geqslant 10 \mathrm{mg} / \mathrm{ml}\right)$.

(5) Increased cough receptor sensitivity (capsaicin concentration eliciting 5 or more coughs (C5) $\leqslant 3.9 \mu \mathrm{M}$ ).

(6) Cough resistant to bronchodilator therapy (oral clenbuterol $40 \mu \mathrm{g} / \mathrm{day}$ plus inhaled procaterol or salbutamol at bedtime and on demand for $\geqslant 1$ week).

(7) No abnormal findings indicative of cough aetiology on chest radiograph

(8) Normal FEV ( $_{1} \geqslant 80 \%$ of predicted value), FVC ( $\geqslant 80 \%$ of predicted value), and $\mathrm{FEV}_{1} / \mathrm{FVC}$ ratio ( $\left.\geqslant 70 \%\right)$.

When all criteria were satisfied, a definite diagnosis of atopic cough was made. If one or more criteria were not satisfied or examined, a diagnosis of probable atopic cough was made when all of the following were present:

(1) Non-productive cough lasting more than 8 weeks without wheezing or dyspnoea.

(2) Cough resistant to bronchodilator therapy.

(3) Presence of one or more findings indicative of atopic constitution as a global feature described above and/or induced sputum eosinophilia ( $2.5 \%$ or more).
(4) Complete relief of cough after treatment with histamine $\mathrm{H}_{1}$ antagonists and/or corticosteroids for 1 month.

Using these diagnostic criteria, patients with atopic cough were divided into two groups: definite atopic cough and probable atopic cough groups.

\section{Cough variant asthma}

The diagnosis of cough variant asthma was made according to the following criteria proposed by the Japanese Cough Research Society:

(1) Isolated chronic non-productive cough lasting more than 8 weeks.

(2) Absence of a history of wheeze or dyspnoea, and no adventitious lung sounds on physical examination.

(3) Absence of postnasal drip to account for the cough.

(4) $\mathrm{FEV}_{1}, \mathrm{FVC}$, and $\mathrm{FEV}_{1} / \mathrm{FVC}$ ratio within normal limits.

(5) Presence of bronchial hyperresponsiveness ( $\mathrm{PC}_{20}<10 \mathrm{mg} /$ $\mathrm{ml})$.

(6) Relief of cough with bronchodilator therapy.

(7) No abnormal findings indicative of cough aetiology on chest radiograph.

All patients with cough variant asthma had been successfully treated with bronchodilators and/or steroids. 
Table 3 Onset of bronchial asthma in a long term follow up of patients with atopic cough and cough variant asthma

\begin{tabular}{llll} 
& \multicolumn{2}{l}{ Onset of typical asthma } & \\
\cline { 2 - 3 } & Yes & No & \\
\hline Atopic cough & & & \\
$\quad \begin{array}{l}\text { Definite } \\
\text { Probable }\end{array}$ & $0(0.0 \%)^{*}$ & $24(100.0 \%)$ & $24 \dagger$ \\
$\quad 1(1.7 \%)^{* *}$ & $57(98.3 \%)$ & 58 \\
Total & $1(1.2 \%)$ & $81(98.8 \%)$ & $82 \S$ \\
$\quad$ With BDP & $2(5.7 \%)$ & $33(94.3 \%)$ & $35 \ddagger$ \\
Without BDP & $6(30.0 \%)$ & $14(70.6 \%)$ & 20 \\
Total & $8(14.5 \%)$ & $47(85.5 \%)$ & 55
\end{tabular}

$\mathrm{NS}=$ statistically not significant; $\mathrm{BDP}=$ beclomethasone dipropionate

${ }^{*} \mathrm{p}=0.0030,{ }^{*} \mathrm{p}<0.0001 v$ cough variant asthma without BDP; †difference between patients with definite and probable atopic cough not significant; $\ddagger p=0.014 v$ cough variant asthma without BDP; $\S p=0.002 v$ all patients with cough variant asthma.

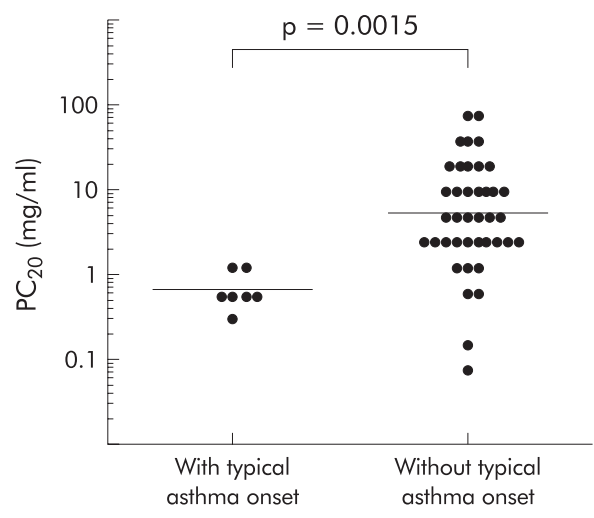

Figure 1 Methacholine bronchial responsiveness $\left(\mathrm{PC}_{20}\right)$ before treatment in patients with cough variant asthma with and without onset of typical asthma. $\mathrm{PC}_{20}$, provocative concentration of methacholine causing a $20 \%$ or greater fall in forced expiratory volume in 1 second $\left(\mathrm{FEV}_{1}\right)$, was determined before treatment in 47 of 55 patients with cough variant asthma.

The efficacy of bronchodilator treatment described above was assessed according to the following criteria:

(1) "Excellent" when cough totally resolved.

(2) "Good" when sleep and daytime quality of life were improved.

(3) "Fairly good" when severity and frequency of cough were somewhat decreased.

(4) "Poor" when cough was unchanged.

An assessment of "excellent" or "good" was judged as effective.

Pulmonary function, cough sensitivity, bronchial reversibility, and bronchial responsiveness were measured in that order within 1 month of the first visit (table 2). FVC, FEV 1 and flowvolume curves were measured using a dry wedge spirometer (Chestac 11, Chest Co Ltd, Tokyo, Japan). Spirometric tests were performed and evaluated according to ATS criteria. ${ }^{12}$ The capsaicin cough threshold (C5) was measured as an index of cough sensitivity ${ }^{13}{ }^{14}$ and $\mathrm{PC}_{20}$ was measured as an index of nonspecific bronchial responsiveness. ${ }^{15}$ Bronchial reversibility was determined from spirometric tests performed before and 30 minutes after inhalation of $300 \mu \mathrm{g}$ salbutamol sulphate following intravenous administration of $250 \mathrm{mg}$ aminophylline.

Eleven patients diagnosed with definite atopic cough, 19 with probable atopic cough, 26 with cough variant asthma treated with BDP, and 11 with cough variant asthma not treated with BDP had been seen regularly as outpatients; the onset of typical asthma and recurrence of isolated nonproductive cough were retrospectively determined from their clinical records. The outcome in other patients who had been seen by their family doctors or who had discontinued treatment was assessed by direct telephone interview with two of the authors ( $\mathrm{HO}, \mathrm{YN})$. The onset of typical asthma was defined as wheezing and/or a dyspnoeic attack responding to inhaled $\beta_{2}$ agonists. Cough was considered recurrent when an isolated non-productive cough lasted for more than 2 weeks despite upper respiratory infection.

\section{Data analysis}

All data except $\mathrm{PC}_{20}$ and $\mathrm{C} 5$ were presented as mean (SD) values. $\mathrm{PC}_{20}$ and $\mathrm{C} 5$ data were expressed as geometric mean (GSEM) values. Differences in the prevalence of outcomes between groups were determined by $\chi^{2}$ test. Differences in $\mathrm{PC}_{20}$ and C5 between groups were analysed by non-parametric one-way analysis of variance (ANOVA) using logarithmically transformed values.

\section{RESULTS}

Long term inhaled steroid therapy (BDP $400 \mu \mathrm{g} /$ day) for control of cough had been used by two patients with definite atopic cough and one with probable atopic cough. Thirty five patients with cough variant asthma had used long term inhaled BDP therapy (median $400 \mu \mathrm{g}$ /day, range 200-800; $\mathrm{BDP}+$ group) and 20 had not (BDP-group).

The median follow up period was 5.3 years (range $1-8.8$, mean (SD) $5.0(2.4)$ ) in the definite atopic cough group, 4.2 years (range 1-11.5, mean (SD) 4.7 (3.0)) in the probable atopic cough group, 3.5 years (range 1-11.1, mean (SD) 4.8 (3.4)) in the group with BDP + cough variant asthma, and 3.9 years (range 1-12.4, mean (SD) $5.2(4.0)$ ) in the group with $\mathrm{BDP}-$ cough variant asthma.

In patients with cough variant asthma the onset of typical asthma occurred in two of the 35 patients in the $\mathrm{BDP}+$ group and in six of the 20 patients in the BDP- group (difference $24.3 \%, 95 \%$ CI 2.8 to $45.8, \mathrm{p}<0.02$; table 3 ). In patients with atopic cough the onset of typical asthma was confirmed in only one patient in the probable group and in none of the patients with definite atopic cough. The onset of typical asthma was thus significantly less prevalent in patients with atopic cough than in those with cough variant asthma (both $\mathrm{BDP}+$ and BDP-groups) (difference $13.3 \%, 95 \% \mathrm{CI}-13.0$ to 39.6, $\mathrm{p}=0.002$; table 3). The onset of typical asthma in patients with definite atopic cough and with probable atopic cough was significantly less prevalent than in the BDP-group (difference $30.0 \%, 95 \%$ CI 9.9 to $50.1, p=0.0030$ and $28.2 \%, 95 \%$ CI 7.8 to $48.6, \mathrm{p}<0.0001$, respectively), but did not differ from that in the BDP+ cough variant asthma group.

The same analysis was performed on patients who were regularly seen at our outpatient clinics. The onset of typical asthma was not seen in any of the 11 patients with definite 
atopic cough or the 19 with probable atopic cough, but occurred in two of the 26 patients with BDP+ cough variant asthma and six of the 11 patients with BDP- cough variant asthma. The rate of onset of typical asthma was significantly greater in the BDP-group than in the BDP+ group (difference $46.9 \%, 95 \%$ CI 15.7 to $78.1, p=0.0016$ ).

The rate of recurrence of isolated non-productive cough did not differ significantly between patients with definite atopic cough (12/24), probable atopic cough (30/58), BDP+ cough variant asthma (20/35), and BDP- cough variant asthma (7/20).

Methacholine challenge was carried out before treatment in 47 of the 55 patients with cough variant asthma (fig 1). The geometric mean (GSEM) $\mathrm{PC}_{20}$ value was 0.69 (1.20) $\mathrm{mg} / \mathrm{ml}$ in patients with cough variant asthma who developed typical asthma, which was significantly lower than that in patients with cough variant asthma who did not develop typical asthma (5.18 (1.28) mg/ml; $\mathrm{p}=0.0015)$.

\section{DISCUSSION}

This study was neither randomised nor controlled, particularly with regard to the assessment of bronchodilator therapy efficacy which was a key criterion for the diagnosis of cough variant asthma. In our experience this assessment is not difficult. When sleep and daytime quality of life are improved with treatment, efficacy can be judged as "good", leading to the diagnosis of cough variant asthma. Indeed, bronchial responsiveness, ${ }^{21617}$ bronchial reversibility, ${ }^{2617}$ and cough sensitivity ${ }^{1617}$ were significantly different between patients with atopic cough and those with cough variant asthma diagnosed on this assessment in our previous studies, as well as in the present study (probable atopic cough $v$ cough variant asthma in table 1 ).

Cough variant asthma was first described by Glauser. ${ }^{18}$ The only presenting symptom is isolated chronic cough responsive to bronchodilator treatment. Recognition of cough variant asthma is clinically important because bronchodilator treatment is only effective in cough variant asthma. Bronchodilators usually exert no antitussive effect in other causes of isolated chronic cough. ${ }^{19}$

Atopic cough is a new clinical entity that we have proposed as a cause of isolated chronic non-productive cough. ${ }^{251617}$ Although the character of the cough is similar in both atopic cough and cough variant asthma (except for the response to bronchodilator therapy), they differ with regard to pathophysiological features. BAL eosinophilia is present in cough variant asthma ${ }^{6}$ but absent in atopic cough, ${ }^{5}$ whereas bronchial tissue and induced sputum eosinophilia are common in both. ${ }^{5616}$ The defining physiological feature is increased cough sensitivity without BHR in atopic cough, and BHR without cough hypersensitivity in cough variant asthma. ${ }^{17}$ Although other researchers have reported that cough sensitivity was heightened and recovered to a normal level following successful treatment of cough variant asthma, ${ }^{20}$ it should be recognised that cough sensitivity is entirely independent of bronchial responsiveness ${ }^{14}$ or bronchomotor tone, ${ }^{21}$ and that it is within normal limits in typical asthma. ${ }^{14}$ We therefore suggest that increased cough sensitivity is not a primary feature of cough variant asthma.

Nearly $30 \%$ of patients with cough variant asthma eventually develop typical asthma. ${ }^{7-9}$ In this study the onset of typical asthma was seen in two of 35 patients taking long term BDP and in six of 20 patients not receiving treatment with BDP. The rate in patients without BDP is consistent with previously reported rates. ${ }^{7-9}$ It is noteworthy that the rate of onset of typical asthma was significantly lower in patients treated with BDP, which suggests the usefulness of long term inhaled steroids as an intervention against cough variant asthma. It is believed that both early diagnosis and intervention are important in controlling asthma. ${ }^{11}$ As cough variant asthma is thought to be a precursor of typical asthma, early intervention for cough variant asthma may be as important as in mild asthma. To address this issue, longitudinal investigations studying the effect of inhaled steroids on the long term decline of pulmonary function are needed, as are studies delineating the effect on both symptoms and transformation to typical asthma.

The onset of typical asthma was seen in only one of 58 patients with probable atopic cough and in none of 24 patients with definite atopic cough. The patient with probable atopic cough, who developed wheezing following an upper respiratory infection 11.5 years after her first visit, had $\mathrm{BHR}\left(\mathrm{PC}_{20}\right.$ $1.25 \mathrm{mg} / \mathrm{ml}$ ) but not bronchial reversibility $(-3.5 \%$ increase in $\mathrm{FEV}_{1}$ by bronchodilators) or increased diurnal variation in peak expiratory flow rate $(3.6 \%)$. This patient refused a capsaicin cough provocation test. Bronchodilator treatment proved ineffective against her cough, which was successfully treated with the histamine $\mathrm{H}_{1}$ antagonist azelastine. Thus, despite BHR, we diagnosed her as having probable atopic cough, although others might label this case as cough variant asthma. With the exception of this case, the onset of typical asthma was not seen in any patients with atopic cough. These findings, in addition to the pathophysiological differences between atopic cough and cough variant asthma, support the hypothesis that atopic cough represents a distinct clinical entity. The absence of transformation to typical asthma from definite atopic cough can be explained by BHR within normal limits $^{25}{ }^{16} 17$ and eosinophilic inflammation limited to the large airways. ${ }^{522}$ Although BHR was increased in 15 of 48 patients with probable atopic cough who underwent methacholine challenge, typical asthma occurred in only one patient. This low prevalence of typical asthma may be explained by the low level of BHR (median $\mathrm{PC}_{20} 2.5 \mathrm{mg} / \mathrm{ml}$, range 1.25-5.0) and the absence of eosinophilic inflammation of peripheral airways. ${ }^{522}$

A diagnosis of cough variant asthma has been made based on the efficacy of steroids by some investigators, ${ }^{15}{ }^{23-25}$ but steroids are effective not only in cough variant asthma but also in atopic cough. It is therefore likely that the use of steroid efficacy as a criterion to diagnose cough variant asthma may accidentally misclassify patients who actually have atopic cough. This may account for the increased cough sensitivity in patients with cough variant asthma studied by McGarvey and colleagues. ${ }^{20}$

Eosinophilic bronchitis without asthma (EB), as originally described by Gibson et al, ${ }^{26}$ seems to resemble atopic cough. The diagnostic criteria used by Gibson (personal communication) were sputum or induced sputum eosinophilia $(>2.5 \%)$ and lack of physiological or symptomatic features of asthma with the exception of cough. Gibson $e t$ al ${ }^{27}$ have reported a similar degree of BAL eosinophilia and granulocytemacrophage colony stimulating factor and interleukin 5 gene expression in patients with EB as in those with asthma, which suggests that EB and atopic cough are not similar. ${ }^{28}{ }^{29}$ On the other hand, Brightling et $a l^{30}$ found that cough sensitivity to capsaicin was heightened in patients with EB diagnosed by induced sputum eosinophilia and normal bronchial responsiveness, suggesting that EB and atopic cough resemble each other. Further investigation is required to elucidate the relationship between atopic cough and EB. ${ }^{10} 2829$

In conclusion, this study has shown that the onset of typical asthma occurred significantly less frequently in patients with atopic cough than in those with cough variant asthma. In addition, long term inhaled steroids significantly decreased the development of typical asthma in patients with cough variant asthma. If mild asthma benefits from early intervention with long term inhaled steroids, it will be also useful for cough variant asthma. As atopic cough differs from cough variant asthma with regard to both outcome and pathophysiological features, we strongly recommend that atopic cough is recognised as a new clinical entity characterised by isolated chronic non-productive cough. 


\section{Authors' affiliations}

M Fujimura, Third Department of Internal Medicine, Kanazawa University School of Medicine, Kanazawa, Japan

H Ogawa, Y Nishizawa, Division of Internal Medicine, Ishikawa-ken Saiseikai Kanazawa Hospital, Kanazawa, Japan

K Nishi, Division of Pulmonary Medicine, Ishikawa Prefectural Central Hospital, Kanazawa, Japan

\section{REFERENCES}

1 Irwin RS, Boulet LP, Cloutier MM, et al. Managing cough as a defense mechanism and as a symptom: a consensus panel report of the American College of Chest Physicians. Chest 1998;114(Suppl):133-81S.

2 Fujimura M, Sakamoto S, Matsuda T. Bronchodilator-resistive cough in atopic patients: bronchial reversibility and hyperresponsiveness. Intern Med 1992;31:447-52.

3 Fujimura M. Cough variant asthma and related disorders: atopic cough (in Japanese). Arerugi no rinsho 1996;16:22-7.

4 Nishi K, Amemiya T, Mizuguchi M, et al. A case of gastro-esophageal reflux-associated chronic cough. Nihon Kyobu Shikkan Gakkai Zasshi 1995;33:652-9.

5 Fujimura $M$, Ogawa $H$, Yasui $M$, et al. Eosinophilic tracheobronchitis and airway cough hypersensitivity in chronic non-productive cough. Clin Exp Allergy 2000;30:41-7.

6 Niimi A, Amitani R, Suzuki K, et al. Eosinophilic inflammation in cough variant asthma. Eur Respir J 1998,11:1064-9.

7 Corrao WM, Braman SS, Irwin RS. Chronic cough as the sole presenting manifestation of bronchial asthma. N Engl J Med 1979;300:633-7.

8 Johnson D, Osborn LM. Cough variant asthma: a review of the clinical literature. J Asthma 1991;28:85-90.

9 Braman SS, Corrao WM. Chronic cough; diagnosis and treatment. Primary Care 1985;12:217-25.

10 Gibson PG, Fujimura M, Niimi A. Eosinophilic bronchitis: clinical manifestations and implications for treatment. Thorax 2002:57:178-82.

11 National Institutes of Health. Expert panel report 2: Guidelines for the diagnosis and management of asthma. Bethesda, MD: National Institutes of Health, 1997.

12 American Thoracic Society. Standardization of spirometry: 1987 update. Am Rev Respir Dis 1987;136:1285-98

13 Fujimura $M$, Sakamoto S, Kamio Y, et al. Sex difference in the inhaled tartaric acid cough threshold in non-atopic healthy subjects. Thorax 1990;45:633-4.

14 Fujimura $M$, Sakamoto $S$, Kamio $Y$, et al. Cough receptor sensitivity and bronchial responsiveness in normal and asthmatic subjects. Eur Respir J 1992:5:291-5.
15 Cockcroft DW, Ruffin RE, Dolovich J, et al. Allergen-induced increase in non-allergic bronchial reactivity. Clin Allergy 1977;7:503-13

16 Fujimura $M$, Songur $N$, Kamio $Y$, et al. Detection of eosinophils in hypertonic saline-induced sputum in patients with chronic nonproductive cough. J Asthma 1997;34:119-26.

17 Fujimura $M$, Kamio Y, Hashimoto T, et al. Cough receptor sensitivity and bronchial responsiveness in patients with only chronic nonproductive cough: in view of effect of bronchodilator therapy. J Asthma 1994;31:463-72

18 Glauser FL. Variant asthma. Ann Allergy 1972;30:457-9.

19 Irwin RS, Corrao WM, Pratter MR. Chronic persistent coughing the adult: the spectrum and frequency of causes and successful outcome of specific therapy. Am Rev Respir Dis 1981;123:413-7.

20 McGarvey LPA, Heaney LG, Lawson JT, et al. Evaluation and outcome of patients with chronic non-productive cough using a comprehensive diagnostic protocol. Thorax 1998;53:738-43.

21 Fujimura $M$, Sakamoto S, Kamio Y, et al. Effects of methacholine-induced bronchoconstriction and procaterol-induced bronchodilation on cough receptor sensitivity to inhaled capsaicin and tartaric acid. Thorax 1992;47:441-5.

22 Fujimura $M$, Nishi K, Ohka T, et al. Bronchial biopsy and sequential bronchoalveolar lavage in atopic cough: in view of the effect of histamine H1-receptor antagonists. Allergology Int 2000;49: 135-42.

23 Doan T, Patterson R, Greenberger PA. Cough variant asthma: usefulness of a diagnostic-therapeutic trial with prednisone. Ann Allergy 1992;69:505-9.

24 Parks DP, Ahrens RC, Humphries T. Chronic cough in childhood: approach to diagnosis and treatment. J Pediatr 1989;115(Suppl):85662.

25 Cheriyan S, Greenberger P, Patterson R. Outcome of cough variant asthma treated with inhaled steroids. Ann Allergy 1994;73:478-80.

26 Gibson PG, Dolovich J, Denburg J, et al. Chronic cough: eosinophilic bronchitis without asthma. Lancet 1989;1:1346-8.

27 Gibson PG, Zlatic K, Scott J, et al. Chronic cough resembles asthma with IL-5 and granulocyte-macrophage colony-stimulating factor gene expression in bronchoalveolar cells. J Allergy Clin Immunol 1998; 101:320-6.

28 Brightling CE, Pavord ID. Eosinophilic bronchitis: what is it and why is it important? Clin Exp Allergy 2000;30:4-6.

29 Fujimura $\mathbf{M}$. Eosinophilic bronchitis is an important cause of chronic cough (letter). Am J Respir Crit Care Med 2000;161:1764-5.

30 Brightling CE, Ward R, Wardlaw $\mathrm{A}$, et al. Airway inflammation, airway responsiveness and cough before and after inhaled budesonide in patients with eosinophilic bronchitis. Eur Respir J 2000;15:682-6. 